\title{
Facebook Commerce (F-Commerce) and French Women: A Gender Perspective
}

\section{Maria Mercanti-Guérin}

Assoc. Prof. Dr., Université Paris 1 Sorbonne Gregor, IAE de Paris

\section{Abstract}

The objective of this exploratory research is to investigate a mode of purchasing, social commerce and its main target, e-shoppers. Social commerce can take different forms: F-commerce, grouped purchases or discounts. Nevertheless, the best way to monetize social media remains the possibility to incite Internet users to promote the products or promotions obtained by their friends. Recommendations coming from friends are the main lever to create interactions between consumers, interactions centered on the purchase. However, many questions remain unanswered, especially regarding social acceptance and the real effectiveness of this type of promotion. In one study conducted on the "La Redoute" brand, we examined the extent to which our sample of women is likely to accept social shopping and, in particular, the product or service recommendations of their friends on their wall.

Keywords: social commerce, routes of persuasion, branding, recommendations, Facebook Commerce, F-commerce

\section{Introduction}

Social commerce is booming. The global social commerce market size is expected to reach USD 3,369.8 billion by $2028^{1}$. Social commerce can be defined as a business practiced within social networks, but it also concerns on-site purchases benefiting from sharing applications or social recommendations. Within the social commerce ecosystem, Facebook is the most important player in this market. More than 80 percent of the so-called social sales are made on this network and its integrated online stores. They constitute the F-commerce (for commerce on Facebook). They are helped by social promotions that have several characteristics: they are viral operations, they are often associated with the world of games and entertainment. These operations are either automatically or voluntarily published on the walls of the participants. The friends of the latter know which brands they are fans of, which

1 https://www.grandviewresearch.com 
promotional operations they participate in, etc. This raises a number of questions: do these promotional mechanisms make friends want to participate? What image does the brand get out of it? Are there phenomena of rejection, since the social network is, for many, intended for exchanges and not for commercial solicitation? What type of mechanism should be favored? Are friends more influenced by close friends than by distant friends? Beyond these issues, social commerce appears to be a typically female phenomenon. The latest studies show that a quarter of women communicate about their purchases via social networks and that this phenomenon is all the more important as it concerns young working women aged 25-352. The phenomenon of "eshoppers" is extensively studied by practitioners and researchers (Chen and al., 2017 ; Wang and al., 2019 ; Fu and al., 2020; Groothuis and al., 2020). Nevertheless, little research studies social commerce from a gender perspective (Rodgers et al.,2003). Therefore, the objective of this research is to better understand the mechanisms of persuasion that can be used by F-commerce with women.

The structure of the paper is as follows. The next section provides the study's theoretical background and hypothesis development. Section 2 reports the data analysis and preliminary findings, which are then discussed and interpreted. The last section provides a summary and makes recommendations for future work.

\section{Facebook commerce, mechanics and results}

According to Li and al. (2017, p 191), social commerce includes "commercial activities facilitated by or conducted through the broad social media and Web 2.0 tools in consumers' online shopping process or business' interactions with their customers". Its extreme diversity (online sales, virality of purchasing behavior, consumer opinions...) makes it difficult to study. Liang et al (2011) mention that, beyond its difficult conceptual delimitation, social commerce suffers from a lack of consideration of its founding concept, which is sharing among friends. According to several studies, online shoppers are likely to share information related to their purchase with their friends. Moreover, information received from friends is considered more reliable than information received from friends. Consumers' shared information, such as ratings, reviews, recommendations, and referrals, has been demonstrated to influence their social commerce use (Zhang, 2016).

Facebook is an important part of social commerce and is expanding access to new social commerce features. The tech giant is building an impressive set of social commerce tools that should make it a leader in the space ${ }^{1}$. Many e-commerce tools are starting to appear on the world's first social network which is in a continuous testing phase in order to select the most efficient mechanics. We will mention Facebook connect, Facebook online stores that allow you to select items or make purchases without leaving the network and Facebook credits, which are promotional

\footnotetext{
1 https://www.businessinsider.com/facebook-dives-into-social-commerce-with-new-features-2020$8 ? \mathrm{IR}=\mathrm{T}$
} 
tools increasingly used by the big e-commerce companies. New functionalities are being studied, such as the "shop with friends" or "buy with my friends" that will be displayed on certain online sales sites and will allow Internet users to see the purchases made by their network. The goal of all these techniques is to sell where the consumer and his friends are. The F-commerce has been notably carried by the success of Facebook credits which represented a kind of virtual currency allowing Internet users to buy virtual objects used in game platforms such as Farmville. Social commerce on Facebook includes several mechanisms that are either traditional promotional mechanisms adapted to social networks or social mechanisms adapted to online commerce. The integration of friends' purchases as a viral element is used in many solutions. The latest launches of Facebook commerce concern Facebook Shops and its second hand market place (Chang and al., 2020).

The literature on user-generated recommendations is rich in lessons learned. It distinguishes between user-generated recommendations (UGC) and word of mouth, which can be spread by individuals who are not users of the product (Cheong and Morrison, 2008). UGC recommendations give more credibility to the information (Johnson and Kaye, 2004), work on interpersonal influence (Johnson and Kaye, 2004), and reduce the risk of making mistakes, particularly for highly involved product purchases (Goldsmith and Horowitz, 2006). Peer recommendations provide available information, which reduces research costs (loss of time) and gives more confidence in the product, especially if it is a low-cost product. Recommendations systems result in (Bhavik et al., 2010) more credibility than the brand's official discourse (1), reducing uncertainty about product quality (2), increasing awareness of the recommended product (3).

Nevertheless, certain conditions must be met regarding the effectiveness of sales recommendations. This effectiveness depends on the strength of recommendations (very favorable), their number, and their position within the site. In addition, they must relate to characteristics that are relatively unknown to be judged as a real value contribution by consumers (Bhavik and al., 2010). Furthermore, the notion of proximity is central to the positive impact of purchasing recommendations. The congruency of construal levels between social distance and temporal distance leads to a greater impact of others' recommendations on consumers' preferences (Zhao and Xie, 2011). The distance between the individuals who recommend and the individuals who follow these recommendations is crucial. This distance can be conceptualized along four axes: temporal distance (is the purchase planned for soon or is it long term?), social distance (is the recommending individual part of my group?), spatial distance (is the recommending individual geographically distant?) (Kim, Zhang, \& Li, 2008).

With regard to temporal distance, it appears that recommendations are more effective in constructing consumer preferences when the purchase is planned in the short term. Moreover, the consumer will rely on recommendations of individuals 
belonging to his social group. Conversely, for an expensive and complex product, consumers will trust individuals outside their social group who are perceived as more expert. These results show that the long-term purchase of a technological or complex product takes little account of the recommendations of family and friends. The social influence therefore differs according to the type of product.

Influence can be defined as a change in an individual's original state due to interpersonal relationships or changes in social factors (Goldsmith \& Horowitz, 2006). It can be of two kinds: normative influence and informational influence. The normative influence can be negative (fear of rejection by the group) or positive (desire to assert one's belonging to the group). Many experiments show that individuals tend to model their behaviour on the dominant behaviour of the group even if the group does not agree with their own views. The informational influence is related to the problem of recommendations. When the individual lacks information or does not feel competent on a subject, he or she will tend to rely on the recommendations of peers. Moreover, the consumption context is a source of interaction and influence between consumers. The geographical context is particularly addressed and, in particular, the spatial environment (Steyer and al., 2006). This spatial environment can be transposed to network issues. An individual's wall is a source of interaction with others within a defined space. This new spatial configuration is linked to the concept of socio-spatial propagation. Thus, the purchase of new products can be propagated by simple vision, propagation from one individual to another, individuals who belong to the same social or geographical group (Whyte, 1954). This importance of social influence is an element to be taken into account in the participation process.

Indeed, the low level of individual participation in branding operations raises questions about the relatively limited impact of social influence.

The different fields of literature allow us to understand the mechanics that can explain the success of these social promotions better (Lăzăroiu and al.,2020). This success is based on :

Operations broadcast between friends in a purely relational context

Interpersonal influence and proximity to the Internet user who is adept at this type of operation

Multidimensional persuasion with an affective, cognitive and conative component

Mechanics focused on play and interactivity that would generate more adhesion than more traditional mechanics.

Mechanics relevant for each target (age, interests) but also different for each gender, with the literature showing large differences in network behaviour between men and women (Grubbs Hoy, Milne, 2010). 


\section{Theoretical and conceptual framework}

Our research question aims to understand the mechanisms of F-commerce among women. This section presents the proposed domains of the conceptual framework:

The degree of acceptance by friends of Internet users of social promotions in an intimate context (the wall) and a priori non-commercial

The ability of users of a social network (in this case Facebook) to influence their friends solely by displaying on their wall their participation in a promotional offer.

The influence of the degree of closeness of friends to the Internet user-participant on their willingness to participate

The impact of the type of promotional operation chosen on the image of the organizing brand

Degree of acceptance of social commerce and influences on the organizing brand

The degree of consumer acceptance of social commerce is relatively little discussed in the literature. Considering social commerce as a form of advertising within a social network, the literature shows that network members feel exploited if there is too much advertising and that they do not wish to be confronted with social experiences interrupted by advertising (Zeng, Huang, and Dou, 2009). Thus, commercial communications within communities created for social sharing and not for consumption lead to a strong sense of intrusiveness (Nutley, 2007). These interferences lead to a sense of perceived loss of control and a feeling of invasion of one's personal space. These reactions translate into a feeling of irritation due to the intrusiveness of these communications. These are, above all, affective reactions. This is why the following hypothesis is proposed:

\section{H1: there is a negative influence of mechanically triggered emotional reactions} on the desire to participate (H1a) and the attitude towards the organizing brand (H1b).

Women who see notifications posted on their Facebook wall indicating that their friend has participated in a promotional operation may find this intrusive and unsuited to the spirit of the social network.

\section{Influence of Social Commerce on Beliefs and Attitudes}

These negative emotional reactions are momentary reactions (Lee \& Lumkin, 1992). Perraud (2011) notes that "perceived irritation is defined as momentary impatience. Furthermore, this would be moderated by the informational value of the advertisement (Lee \& Lumkin, 1992). Thus, taking beliefs into account concomitantly with affective reactions (positive or negative) makes it possible to hypothesize that irritation is the first reaction triggered by exposure to an unsolicited commercial communication, but that it can be followed by an activation of cognitions upon reading the ad. Moreover, these cognitions triggered in an online context have a direct 
influence on attitudes towards the brand and promotional mechanics. The work of Karson and Fisher (2005) has made it possible to transfer the results acquired during research on models of persuasion by showing that the hypothesis of dual mediation (importance of beliefs and attitudes on persuasion) is perfectly observable in an online context. We will also hypothesize that the observed attitude towards promotional mechanics can be measured through the intention to participate. Hence the following hypotheses:

H2: There is a positive influence of beliefs $(\mathrm{H} 2 \mathrm{a})$ on the desire to participate and (H2b) the attitude towards the organizing brand.

Women who see notifications posted on their Facebook wall that their friend has participated in a promotion may find this mechanism interesting and informative, however, and encourage them to participate and have a favorable attitude towards the brand.

\section{H3: There is a positive influence of brand attitude on the willingness to participate.}

Women with a favorable attitude towards the brand will have a stronger desire to participate in the promotion than women with a less favorable attitude.

\section{Interpersonal influence and degree of closeness to friends}

As we have noted in the literature on interpersonal influence, the degree of closeness of friends is an essential element in persuasion. We will only consider the social proximity described by Kim, Zhang, and Li (2008) since it is a proximity based on belonging to a community. Nevertheless, we wanted to introduce a gradation among respondents' friends. Indeed, the continuous growth in the number of average friends per user means that within the same community of friends, some are considered close to the user (friends in real life, family members, etc.) while others are more distant (friends only on Facebook who do not know each other in real life, friends who are geographically distant, etc.). Facebook has adapted to these different configurations by offering to create its own lists of friends and adapts the visibility of their posts according to their status. We will therefore make the following hypothesis :

\section{H4: There is a moderating effect of respondent proximity on all of the links in the model.}

A promotion posted on a close friend's wall will have a stronger incentive effect than a promotion posted on a distant friend's wall.

Moreover, the notion of close or distant friend will be left to the sole discretion of the respondent in order to be closer to the natural conditions of exposure of the network.

The search model is therefore as follows (Figure 1) : 


\section{Figure 1. Search Model of the willingness to participate in social promotion}

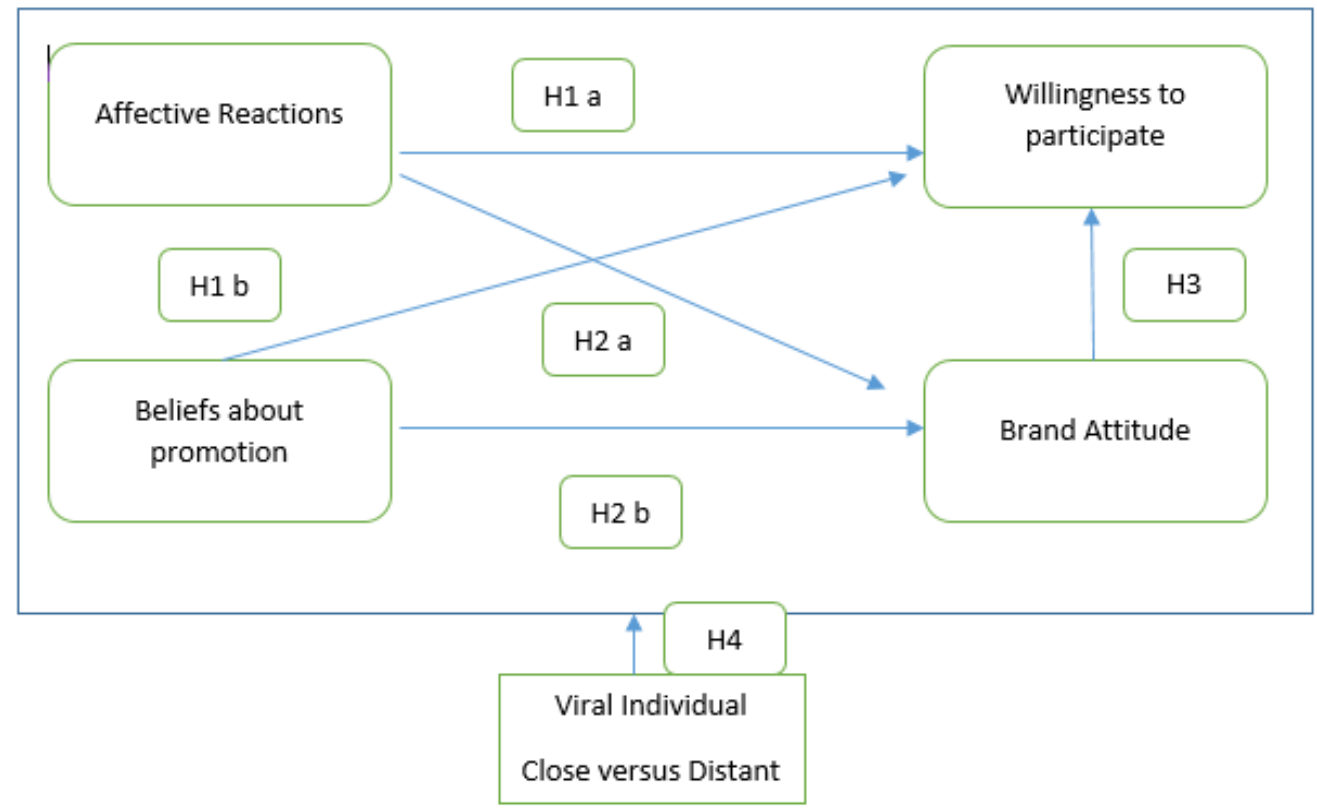

\section{Description of the experiment, results and implications}

\section{Description of the experiment}

The experiment took place in January 2020 on a sample of women (average age 31), online shoppers, La Redoute customers and Facebook members. For each of the respondents, they were asked to give the name of a close friend and that of a distant friend. Two groups described below constituted the experimentation.

Group 1 : Submission of an experimental Facebook wall belonging to a close friend (known as a viral individual). Visualization on his wall of the promotion "Give a second life to your purchases" (see description of the operation, Appendix - Second Hand Operation) ( $\mathrm{n}=101)$

Group 2 : Submission of an experimental Facebook wall belonging to a distant friend (known as a viral individual). Visualization on his wall of the promotion "Give a second life to your purchases" (see description of the operation, Appendix - Second Hand Operation) ( $\mathrm{n}=101)$

Each of the tests was subjected to a multi-group analysis to verify the moderating character of the status of the friend (viral individual) as well as the good quality of the measurement models. Tests of the mean on the variables emotional reaction triggered by the ad, brand attitude and willingness to participate showed a difference in mean only for brand attitude and willingness to participate. The quality of the overall model was also tested. 


\section{Main results}

Negative reactions due to the visualization of a promotion on one's wall are minor, do not generate real rejection in individuals and do not influence either their desire to participate or their attitude towards the brand (H1 a,b not validated).

Beliefs about promotion were measured at two levels: execution (i.e., the form of the promotion) and the message it conveys. It is the beliefs about the execution (attractive, warm) that will have a significant influence on the desire to participate when the viral friend is close. On the contrary, when the consumer is exposed to this type of promotion from a distant friend, his persuasion will be more central, i.e. he will prefer to examine the offer (credible, effective, persuasive message) rather than its form. Nevertheless, examination of the overall model shows that beliefs about promotion have a real influence on the desire to participate and the attitude towards the brand (H2 a,b validated).

Launching an original and fun operation benefits the brand, which appears innovative and modern and increases the desire to participate. When we study its influence within the overall model, it appears that the attitude towards the brand has a significant positive influence on the desire to participate (H3 validated).

The moderating nature of the viral friend status is confirmed (H4 validated). A promotion spread by a close friend must include a strong social aspect in order to make people want to participate, a social aspect that is not present in a more classic promotion such as the "Second Hand" promotion.

\section{Conclusion}

While brands are questioning their presence on Facebook and are starting to consider it as a real sales, promotion and image channel, it is interesting to look at the effects of this presence on the female consumer.

\section{Facebook, a new distribution and promotion channel: what female consumer acceptance?}

Facebook is more and more a place to promote brands. The problem that may arise is the consumer's acceptance of this type of communication within a network, initially designed for exchange and sharing. Won't female consumers end up rejecting brand solicitations that they may consider as distorting the spirit of the social network? It appears that female consumers do not develop (for the moment) a rejection of promotional messages posted on their wall when they come from friends. On the other hand, the premium is given to original, playful promotions. The promotionbrand congruence must be replaced by a search for social network-promotion congruence. Adapting to one's media (Facebook) and codes appears fundamental in the success and acceptance of social promotions. 


\section{Social promotions, effective promotions in case of low involvement}

Most of the promotions developed on La Redoute's Fan page adopt a resolutely social aspect. La Redoute has continuously developed game-oriented promotions: winning its makeover, playing with the Totally Spies, winning the special handsome casting .. These promotions use other participation mechanisms. They are no longer exclusively utilitarian but hedonic and experiential. They are intended to create social bonds. This social link can take place at several levels: between friends, between fans of a brand page, between the consumer and the brand itself.

\section{Influence of gender on the acceptance of social promotion}

Moreover, the difference in behavior between men and women on Facebook has given rise to a large body of literature showing that women are more concerned by the protection of their privacy than men and that they perceive more strongly the risks of revealing their private life on the Internet. Conversely, they are more likely to use Facebook than men. Nevertheless, Grubbs and Milne (2010) show that they accept behavioural advertising based on the use of their personal data and browsing less easily than men. We were able to show that social advertising (one of the many forms of behavioural advertising) is well accepted by the female gender.

These findings make it possible to consider Facebook as a distribution channel in its own right whose social codes must be respected in order to make the most of this network. To conclude this article, we can recall that viral operations are increasingly looking for new communication channels. Indeed, e-mailing and leaflets seem, in many cases, to record poor conversion and acquisition rates. Furthermore, social commerce is being driven to develop thanks to applications or recommendation sites that work on consumer opinions. But the recommendation industry is also in trouble. Few consumers share their shopping experience and it is often the same consumer profiles. Criteo type companies that monetize consumer opinions help to introduce doubt into the veracity of the recommendations put forward. The link between positive recommendations and advertising purchases by e-commerce sites on price comparison sites amplifies this phenomenon. The recommendations we have called passive are new forms of recommendation that work on the conatif: I am a fan of a brand page, I participate in a promotional operation, I buy at a certain place... All these acts of consumption are broadcast on networks (Facebook but also Twitter) and on certain mobile applications. As for influence, it also seeks new sources of understanding. Indeed, the literature on opinion leaders tends to show that leadership is diluted as Internet users frequently speak out. Therefore, the notion of influence by close friends regains an importance that had been diminished by the phenomena of e-reputation centered on a few influential bloggers and seeding techniques. The limits of our research are numerous. They stem from the choice of moderating variables. It would be possible to envisage, in a second step, studying the moderating character of the brand congruence of promotion. Indeed, can technical or B-to-B brands develop the same social mechanisms as consumer brands? Can 
recourse to gambling be a factor in the loss of credibility of certain brands? Finally, the effectiveness of promotional mechanisms should be evaluated according to the habits of Internet users: gamblers versus non-gamblers, fans of price-based or nonprice-based promotions, new customers of the brand or loyal customers.

Among the possible research perspectives, it would be interesting to estimate the impact of these social promotions on the frequentation of e-commerce sites. If their integration into Facebook stores is natural, what about the place reserved for ecommerce sites within more social strategies. Will they have to work on a better integration of the social activities of their consumers by adding more social applications than today or, on the contrary, will they have to limit themselves little by little to a more corporate and less commercial positioning?

\section{References}

[1] Chang, H. H., Lu, Y. Y., \& Lin, S. C. (2020). An elaboration likelihood model of consumer respond action to facebook second-hand marketplace: Impulsiveness as a moderator. Information \& Management, 57 (2), 103171.

[2] Chen, A., Lu, Y., \& Wang, B. (2017). Customers' purchase decision-making process in social commerce: A social learning perspective. International Journal of Information Management, 37(6), 627-638.

[3] Cheong H.J., Morrison M.A. (2008) - Consumers'reliance on Product Information and Recommendations Found in UGC, Journal of Interactive Advertising, $\mathrm{n}^{\circ} 8$.

[4] Fu, J. R., Lu, I. W., Chen, J. H., \& Farn, C. K. (2020). Investigating consumers' online social shopping intention: An information processing perspective. International Journal of Information Management, 54, 102189.

[5] Groothuis, D., Spil, T., \& Effing, R. (2020, January). Facebook marketing intelligence. In Proceedings of the 53rd Hawaii International Conference on System Sciences.

[6] Grubbs Hoy M., Milne G. (2010) - Gender Differences in privacy-related measures for young adult Facebook users, Journal of Interactive Advertising, vol. $10 ., n^{\circ} 2$, p. $28-45$

[7] Harris, L., \& Dennis, C. (2011). Engaging customers on Facebook: Challenges for e-retailers. Journal of Consumer Behaviour, 10(6), 338-346.

[8] Johnson T. J., Kaye B.K. (2004) - Wag the Blog: How Reliance on Traditional media and the Internet Influence Credibility Perceptions of Weblogs Among Blog Users, Journalism \& Mass Communication Quarterly, vol. 81(3), p. 622-642.

[9] Karson E.J., Fisher R.J. (2005), Reexamining and extending the dual mediation hypothesis in an on-line advertising context, Psychology \& Marketing, vol. 22, 4, p. 333-351. 
[10] Kim K., Zhang M., Li X. (2008) - Effects of Temporal and Social Distance on Consumer Evaluations, Journal of Consumer Research, vol. 35 (4), p. 706713.

[11] Lăzăroiu, G., Neguriţă, O., Grecu, I., Grecu, G., \& Mitran, P. C. (2020). Consumers' Decision-Making Process on Social Commerce Platforms: Online Trust, Perceived Risk, and Purchase Intentions. Frontiers in Psychology, 11.

[12] Lee S., Lumpkin J. (1992) - Differences in Attitudes toward TV Advertising : VCR Usage as a Moderator, International Journal of Advertising, vol.11, p. 333-342.

[13] Liang Y.T.H, Li Y.W, Turban E. (2011) - What Drives Social Commerce: The Role of Social Support and Relationship Quality, International Journal of Electronic Commerce, $\mathrm{n}^{\circ}$ 2, p. 69-90.

[14] Lin, X., Li, Y., \& Wang, X. (2017). Social commerce research: Definition, research themes and the trends. International Journal of Information Management, 37(3), 190-201.

[15] Nutley M.(2007) - It's the Influencers, Not the Social Media, That Brands Need to Target, Marketing Week, 3 mai, p.19-21.

[16] Rodgers, S., \& Harris, M. A. (2003). Gender and e-commerce: An exploratory study. Journal of advertising research, 43(3), 322-329.

[17] Steyer A., Garcia-Bardidia R., Quester P. (2006) - Online Discussion Groups as Social Networks: An Empirical Investigation of Word-of-Mouth on the Internet, Journal of Interactive Advertising, $\mathrm{n}^{\circ} 6(2)$, p. 51-59.

[18] Wang, X., Lin, X., \& Spencer, M. K. (2019). Exploring the effects of extrinsic motivation on consumer behaviors in social commerce: Revealing consumers' perceptions of social commerce benefits. International Journal of Information Management, 45, 163-175.

[19] Whyte W.H.(1954) - The Web of Word of Mouth, Fortune, n¹, p.140-143.

[20] Zeng F., Huang L., Dou W. (2009) - Social factors in user perceptions and responses to advertising in online social networking communities, Journal of Interactive Advertising, vol. 10; n¹, p. 1-13.

[21] Zhang, K. Z., \& Benyoucef, M. (2016). Consumer behavior in social commerce: A literature review. Decision Support Systems, 86, 95-108.

[22] Zhao, M., \& Xie, J. (2011). Effects of social and temporal distance on consumers' responses to peer recommendations. Journal of Marketing Research, 48(3), 486-496. 